\title{
Radiation Damage Behavior in Multiphase Ceramics
}

\author{
Kenta K. Ohtaki ${ }^{1}$, Maulik Patel ${ }^{2}$ and Martha L. Mecartney ${ }^{1}$ \\ 1. University of California, Irvine, Chemical Engineering and Materials Science, CA USA \\ 2. University of Tennessee, Knoxville, Materials Science and Engineering, TN USA
}

Ceramics belong to the promising class of radiation damage resistant materials. In particular, nanocrystalline ceramics have been observed to be more tolerant to radiation damage than ceramics with larger grains ${ }^{[1,2,3]}$. In highly radiation damage tolerant materials, the defect annihilation counteracts and mitigates radiation damage. One route to annihilate defects is the migration of point defects to grain boundaries, which act as efficient sinks for defects. Defect migration to the grain boundaries can be enhanced by shortening the distance between the grain boundary sinks and the defects, which is why the finer grain size (nano-crystalline) improves radiation damage tolerance. However, at high temperatures, which typically exist in a nuclear reactor, nano-grains in single-phase materials will grow and irradiation induces additional grain growth. ${ }^{[1,2,3]}$ Once the grains grow larger, the material will no longer be as radiation resistant.

The objective of this study is to engineer new composite materials that will retain the fine grain size under irradiation. The approach is based on using multiple phases of different chemical compositions that inhibit grain growth by blocking the diffusion pathway between like phases. ${ }^{[4]}$ We have selected a 3-phase ceramic that consist of yittria stabilized zirconia (YSZ), alumina $\left(\mathrm{Al}_{2} \mathrm{O}_{3}\right), \mathrm{Mg}$-spinel $\left(\mathrm{MgAl}_{2} \mathrm{O}_{4}\right)$. The radiation induced modifications and defects in each of the single phases have been widely studied ${ }^{[1,3,5,6]}$. 3-phase composite of $8 \mathrm{~mol} \%$ yittria stabilized zirconia (8YSZ), $\mathrm{Al}_{2} \mathrm{O}_{3}$ and $\mathrm{MgAl}_{2} \mathrm{O}_{4}$ with grain size of $500 \mathrm{~nm}$ were sintered by 2-step sintering with $1450{ }^{\circ} \mathrm{C}$ and 5 hours dwelling at $1325^{\circ} \mathrm{C}$ and single crystals of each composition were irradiated at $650{ }^{\circ} \mathrm{C}$ with $4 \mathrm{MeV}$ Si ion beam with fluent of $1 \times 10^{16}$ atom/ $/ \mathrm{cm}^{2}$. Single crystals of each phase were also irradiated to demonstrate the extreme condition with large grain size (no grain boundary).

GIXRD, SEM and TEM were used to analyze microstructural changes and crystals structural changes in irradiated samples. There was no phase transformation or grain growth detected by XRD and SEM in 3phase sample. All phases formed dislocation loops in single crystals (Fig. 1) accumulated at the damage peak region, which was estimated to be 1.5-2 $\mu \mathrm{m}$ from the surface. Especially in $\mathrm{Al}_{2} \mathrm{O}_{3}$, the loops were found throughout the damaged zone. In 3-phase sample, $8 \mathrm{YSZ}$ grains and $\mathrm{MgAl}_{2} \mathrm{O}_{4}$ grain showed high radiation damage tolerance by having less dislocation loops whereas $\mathrm{Al}_{2} \mathrm{O}_{3}$ has dislocation loops throughout the damaged zone as in the single crystal (Fig. 1). In 8YSZ grains, intrinsic defects and/or damage from sample preparation using focused ion beam give strong contrast other than damage due to irradiation, which makes it difficult to analyze the dislocation loops generated by the irradiation. Regardless, a band of region with dislocation loops was not observed. In $\mathrm{MgAl}_{2} \mathrm{O}_{4}$ grains, dislocation loop density is lower than in single crystal (Fig. 1 and 2). For $8 \mathrm{YSZ}$ and $\mathrm{MgAl}_{2} \mathrm{O}_{4}$ grains, having grain boundaries increased radiation damage tolerance. The high radiation damage tolerance, especially in single crystals, for $\mathrm{YSZ}$ and $\mathrm{MgAl}_{2} \mathrm{O}_{4}$ is due to their intrinsic properties ${ }^{[7,8]}$. The scope of this study will be to seek for the grain size with which materials with radiation damage tolerance such as $\mathrm{Al}_{2} \mathrm{O}_{3}$ have less damage. 
References

[1] T. D. Shen et al. Appl. Phys. Lett. 90 (2007), 263115.

[2] A. Misra et al. Jom 59 (2007), 62-65.

[3] S. Dey et al. Sci. Rep. 5 (2015), 7746.

[4] B. Kim et al. Nature 413 (2001), 288-291.

[5] S. Zinkle Nucl. Instrumnt Methods Phys. Res. B (1998), 737-746.

[6] J. M. Costantini et al. J. Nucl. Mater. 440 (2013), 508-514.

[7] L. W. Hobbs et al. J. Nucl. Mater. 216, (1994), 291-321.

[8] F. W. Clinered et al. J. Nucl. Mater 108 and 109, (1982), 655-670.

[9] This material is based upon work supported by the Department of Energy under Award Number DE-NE0000711. The authors would like to thank Prof. Yanwen Zhang and Miguel Crespillo for conducting the ion irradiation experiments.

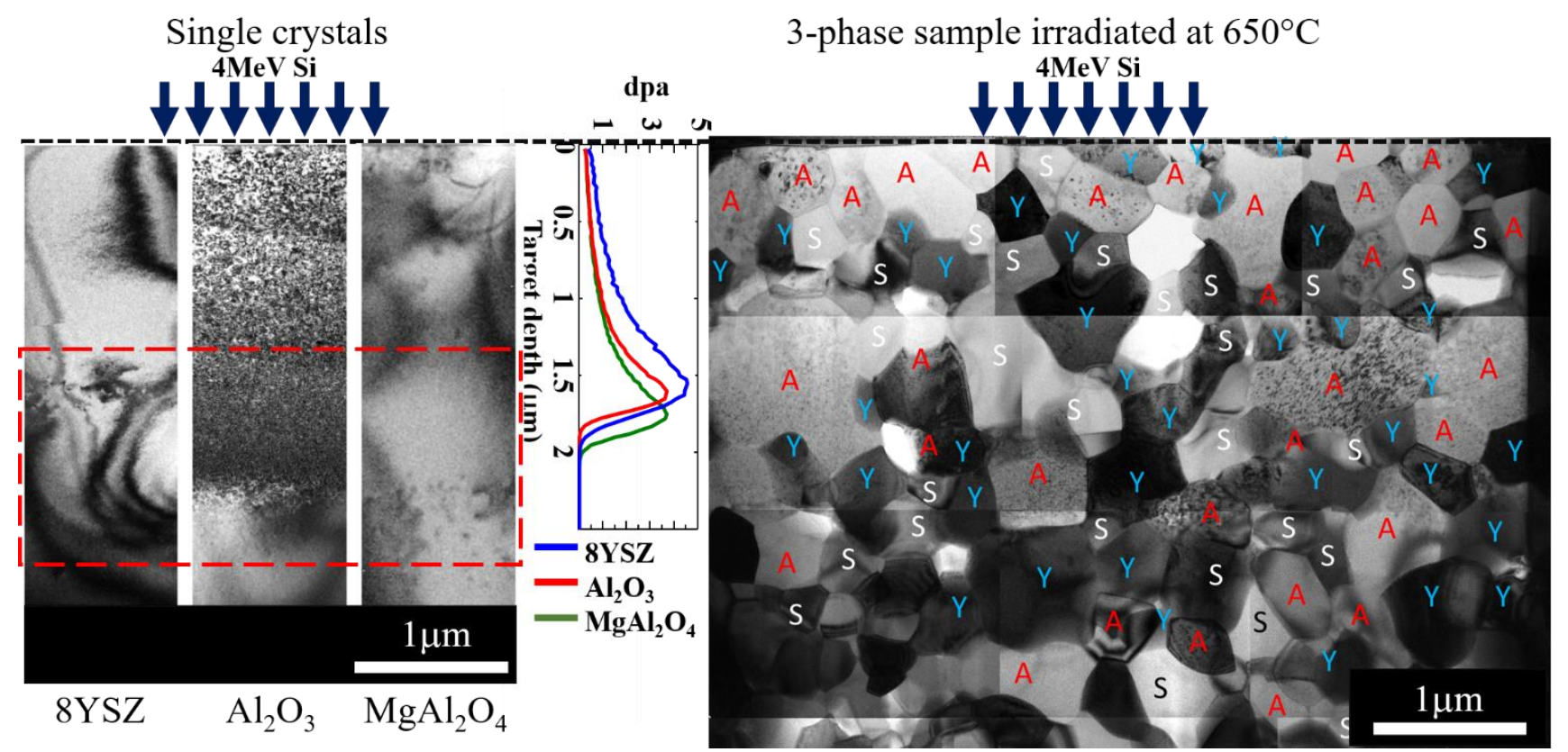

Figure 1. BF TEM images of single crystals and 3-phase irradiated with $4 \mathrm{MeV}$ Si ions at $650{ }^{\circ} \mathrm{C}$. Red dotted box indicates the damage accumulated region with high dislocation density. The inserted graph indicates damage distribution with respect to target depth estimated by SRIM.

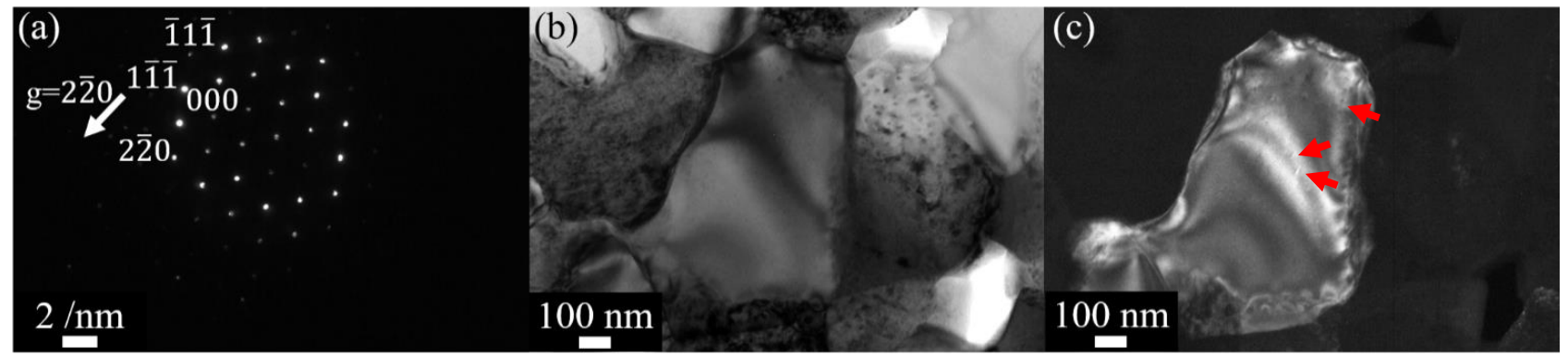

Figure 2. $\mathrm{SAD}(\mathrm{a}), \mathrm{BF}(\mathrm{b})$ and $\mathrm{DF}(\mathrm{c})$ image of $\mathrm{MgAl}_{2} \mathrm{O}_{4}$ grain in damaged region. $\mathrm{g}=2 \overline{2} 0$ near [110]. Red arrows indicates traces of dislocation loops. 